\section{POS0188 DISEASE ACTIVITY OUTCOME MEASURES ARE ONLY AVAILABLE IN HALF OF THE ELECTRONIC MEDICAL FILES OF PATIENTS WITH AXIAL SPONDYLOARTHRITIS FOLLOWED IN AN OUTPATIENT CLINIC: THE RESULTS OF AN AUDIT OF A TERTIARY- CARE RHEUMATOLOGY DEPARTMENT.}

\section{E. Portier ${ }^{1}$, M. Dougados ${ }^{1}$, C. Roux ${ }^{1}$, A. Moltó ${ }^{1}{ }^{1}$ Cochin Hospital,} Rheumatology, Paris, France

Background: Current recommendations for management of patients with axial Spondylarthritis (axSpA) include regular collection of validated disease activity outcomes.

Objectives: This study aimed at evaluating the proportion of patients for whom the elements allowing the calculation of the validated outcome measures were available on the visits reported on the electronic medical records (EMR) and the factors associated with the presence of such information on the EMR.

Methods: This was a cross-sectional and monocentric observational study conducted in a tertiary-care rheumatology department, EULAR center of excellence and ASAS center. We performed a systematic electronic search among all patients with a SpA diagnosis code who attended an outpatient visit between February 1st, 2018 and February 28th, 2019. Thereafter, a manual search was performed in order to check whether disease activity outcome measures (or the elements allowing its calculation): BASDAI individual questions, Disease activity Global, CRP, BASDAI and ASDAS) were reported on EMR. Patient's and physician's demographics disease characteristics (including treatment) and whether the patient had participated in a systematic review were also collected. A descriptive analysis of the percentage of EMR with available outcomes was performed, and the characteristics of patients in whom these measures were available/were not available evaluated by univariable and multivariable analysis (including only variables with $p$ $<0,10$ on the univariate)

Results: 320 EMR of axSpA patients seen in the outpatient clinic were screened and selected. Among them, $178(55.6 \%)$ had at least one disease activity outcome measure reported, while $144(45 \%)$ and $123(38.4 \%)$ had a BASDAI and an ASDAS reported, respectively. The most frequently reported disease activity items were duration of morning stiffness $(n=230,72 \%)$ and CRP $(n=224,70 \%)$. Only previous participation on an educational program for self-assessment was found to be independently associated with a reported disease activity outcome: among the patients participating in such program, 93.1\% $(n=27 / 29)$ had a disease activity measure available, compared to $51.9 \%(n=151 / 291)$ in those who did not participate in such program $(p<0.001)$ (Table 1$)$

Conclusion: Implementation of recommendations with regard to regularly collecting disease activity outcome measures is not optimal. The participation in educational programs including self-assessment educational programs might be one of the keys to improve such implementation.

REFERENCES:

[1] Smolen JS, Braun J, Dougados M, Emery P, Fitzgerald O, Helliwell P, et al. Treating spondyloarthritis, including ankylosing spondylitis and psoriatic arthritis, to target: recommendations of an international task force. Ann Rheum Dis 2014;73:6-16. https://doi.org/10.1136/annrheumdis-2013-203419.

[2] van der Heijde D, Ramiro S, Landewé R, Baraliakos X, Van den Bosch F, Sepriano A, et al. 2016 update of the ASAS-EULAR management recommendations for axial spondyloarthritis. Ann Rheum Dis 2017;76:978-91. https://doi.org/10.1136/annrheumdis-2016-210770.

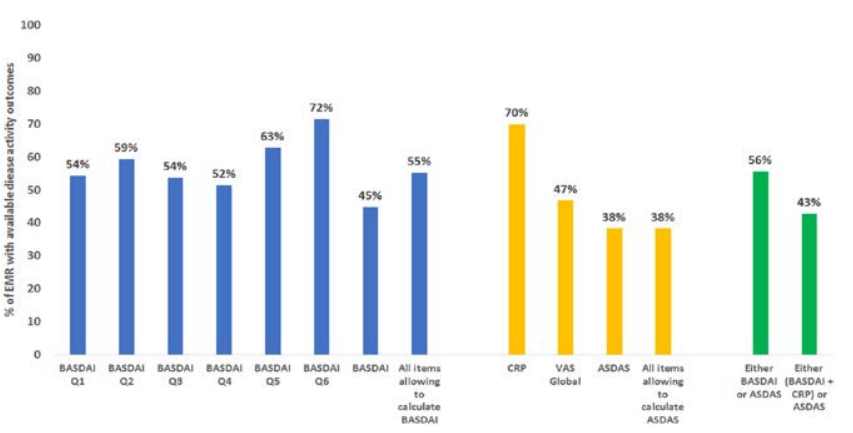

Figure 1. Frequency of disease activity measures reporting in the Electronic Medical Record of patients with axial Spondyloarthritis, followed in a tertiary care rheumatology department outpatient clinic

Disclosure of Interests: Elodie Portier: None declared, Maxime Dougados: None declared, Christian Roux: None declared, Anna Moltó Consultant of: Abbvie, BMS, MSD, Pfizer, Lilly, UCB Novartis, Grant/research support from: Pfizer
Table 1. Factors associated with the presence of a reported disease activity measures on the electronic medical file of patients with axial SpA

\begin{tabular}{|c|c|c|c|c|c|}
\hline & $\begin{array}{c}\text { Total } \\
(n=320)\end{array}$ & $\begin{array}{l}\text { At least one } \\
\text { disease } \\
\text { activity } \\
\text { measure } \\
\text { available } \\
\text { (n=178) }\end{array}$ & $\begin{array}{l}\text { No disease } \\
\text { activity } \\
\text { measure } \\
\text { available } \\
(n=142)\end{array}$ & $\begin{array}{l}\text { Univariable } \\
\text { p-value }\end{array}$ & $\begin{array}{c}\text { Multivariable } \\
\text { analysis p } \\
\text { value }\end{array}$ \\
\hline Age (years) & $46.2(14.0)$ & $46.8(14.2)$ & $45.5(13.8)$ & 0.404 & - \\
\hline Disease duration (years) & $13.3(11.8)$ & $13.8(12.4)$ & $12.4(11.0)$ & 0.339 & - \\
\hline Male gender & $186(58.1 \%)$ & 96 (53.9\%) & $90(63.4 \%)$ & 0.112 & - \\
\hline University studies ( $n=276$ ) & $149(46.6 \%)$ & $87(48.9 \%)$ & $62(43.7 \%)$ & 0.637 & - \\
\hline $\begin{array}{l}\text { Radiographic sacroilititis } \\
(n=257)\end{array}$ & $171(66.5 \%)$ & $101(56.7 \%)$ & 70 (49.3\%) & 0.993 & - \\
\hline MRI sacroiliitis ( $n=214$ ) & $169(52.8 \%)$ & $97(54.5 \%)$ & 72 (50.7\%) & 0.34 & - \\
\hline HLA B27 positive $(n=267)$ & $196(61.2 \%)$ & $118(66.3 \%)$ & $78(54.9 \%)$ & 0.826 & - \\
\hline Current bDMARD & $199(62.2 \%)$ & $116(65.2 \%)$ & $83(58.5 \%)$ & 0.265 & - \\
\hline Age of Rheumatologist & $45.5(8.85)$ & $44.4(8.47)$ & $47.0(9.15)$ & 0.011 & - \\
\hline $\begin{array}{l}\text { Participation in a holistic } \\
\text { systematic review }\end{array}$ & $29(9.1 \%)$ & $27(15.2 \%)$ & $2(1.5 \%)$ & $<0.001$ & 0.001 \\
\hline
\end{tabular}

DOI: 10.1136/annrheumdis-2021-eular.2120

\begin{tabular}{|l}
\hline POS0189 \\
SERUM IFNA CONCENTRATIONS MEASURED \\
WITH SINGLE-MOLECULE ARRAY TECHNOLOGY \\
IN SJÖGREN'S SYNDROME REFLECT BLOOD \\
INTERFERON-STIMULATED GENE EXPRESSION
\end{tabular}

E. Huijser ${ }^{1}$, J. Göpfert ${ }^{2}$, Z. Brkic ${ }^{3}$, C. G. Van Helden-Meeuwsen ${ }^{1}$, S. Jansen ${ }^{1}$, T. Mandl $^{4}$, P. Olsson ${ }^{4}$, B. Schrijver ${ }^{1}$, M. W. Schreurs ${ }^{1}$, P. L. Van Daele ${ }^{1,3}$, W. A. Dik ${ }^{1}$, M. Versnel ${ }^{1} .{ }^{1}$ Erasmus MC, University Medical Center Rotterdam, Immunology, Rotterdam, Netherlands; ${ }^{2}$ NMI Natural and Medical Sciences Institute at the University of Tübingen, Biochemistry, Reutlingen, Germany; ${ }^{3}$ Erasmus MC, University Medical Center Rotterdam, Internal Medicine, Division of Clinical Immunology, Rotterdam, Netherlands; ${ }^{4}$ Lund University, Internal Medicine - Epidemiology, Lund, Sweden

Background: Type I interferon (IFN-I) activation is a prominent feature of several Rheumatic and Musculoskeletal Diseases (RMDs) including primary Sjögren's syndrome (pSS), systemic lupus erythematosus (SLE) and systemic sclerosis (SSc). Ultrasensitive single-molecule array (SiMoA) technology has facilitated the measurement of subfemtomolar concentrations of IFNs [1-3].

Objectives: Here, we tested the performance of a commercially available SiMoA kit for detection of IFN $\alpha$ in serum from pSS, SLE, and SSc and correlated serum IFN $\alpha$ to whole blood IFN-stimulated gene (ISG) expression.

Methods: Serum IFN $\alpha 2$ was measured in healthy controls $(\mathrm{HC} ; \mathrm{n}=68)$ and patients with pSS $(n=85, n=110)$, SLE $(n=24)$ and SSc $(n=23)$ using a ready-touse IFN $\alpha$ SiMoA kit on a HD-X Analyzer. IFN-I activation was additionally determined from paired samples of whole blood IFN-stimulated gene (ISG) expression of IFI44, IFI44L, IFIT1, IFIT3, and MxA by RT-PCR or MxA-ELISA.

Results: Serum IFN $\alpha 2$ levels were elevated in pSS (median $=61.3 \mathrm{fg} / \mathrm{mL}$ ) compared to $\mathrm{HC}$ (median $<5 \mathrm{fg} / \mathrm{mL}$ ) and SSc (median = $11.6 \mathrm{fg} / \mathrm{mL}$ ), lower compared to SLE (median $=313.5 \mathrm{fg} / \mathrm{mL}$ ), and positively correlated to whole blood ISG expression ( $r \mathrm{~s}=0.71-0.76, \mathrm{p}<0.001$ ). Comparable to MxA-ELISA (AUC=0.93), IFN $\alpha 2$ SiMoA identified pSS with high ISG expression (AUC=0.90) with $80-93 \%$ specificity and $71-84 \%$ sensitivity. Blinded validation in an independent pSS cohort yielded a comparable accuracy of $89 \%$. Multiple linear regression indicated independent associations of autoantibodies, IgG, and use of hydroxychloroquine with serum IFN $\alpha 2$ concentrations in pSS. Confirming the literature [4], serum IFN $\alpha 2$ levels were lower in SLE patients in remission (DORIS classification) compared to patients not in remission.

Conclusion: Thus, SiMoA serum IFN $\alpha 2$ reflects blood ISG expression in pSS SLE and SSc. In light of IFN-targeting treatments, SiMoA could potentially be applied for patient stratification or high-throughput retrospective analysis of stored clinical trial material.

REFERENCES:

[1] Rissin, D.M.; Kan, C.W.; Campbell, T.G.; Howes, S.C.; Fournier, D.R.; Song L.; Piech, T.; Patel, P.P.; Chang, L.; Rivnak, A.J., et al. Single-molecule enzyme-linked immunosorbent assay detects serum proteins at subfemtomolar concentrations. Nat. Biotechnol. 2010, 28, 595-599.

[2] Wilson, D.H.; Rissin, D.M.; Kan, C.W.; Fournier, D.R.; Piech, T.; Campbell, T.G.; Meyer, R.E.; Fishburn, M.W.; Cabrera, C.; Patel, P.P., et al. The Simoa HD-1 Analyzer: A Novel Fully Automated Digital Immunoassay Analyzer with Single-Molecule Sensitivity and Multiplexing. Journal of Laboratory Automation 2015, 21, 533-547. DOI: 10.1177/2211068215589580. 